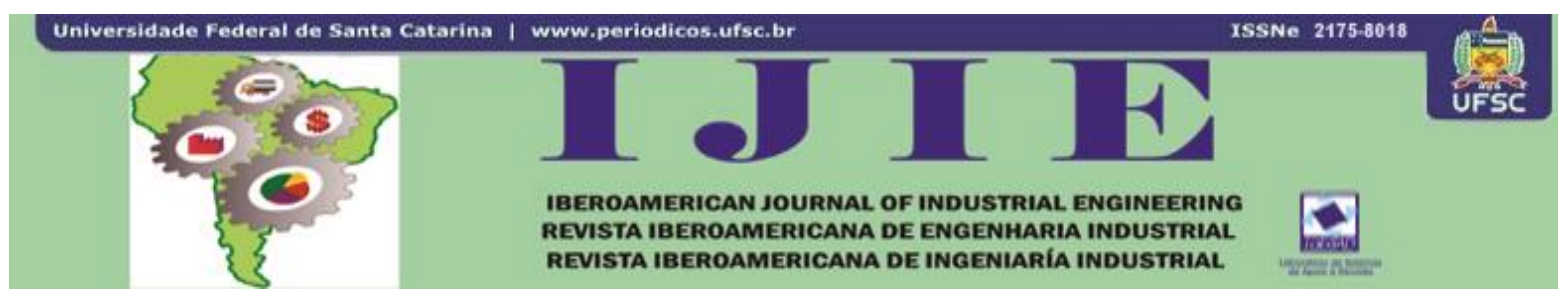

\title{
COMPOSABILITY MODEL IN A DISTRIBUTED SIMULATION ENVIRONMENT FOR SUPPLY CHAIN
}

\author{
Maria del Milagro Gutierrez ${ }^{1}$ \\ Horacio Pascual Leone ${ }^{2}$
}

\begin{abstract}
Distributed simulation becomes popular through the use of HLA standard and the necessity of sharing resources. Nevertheless, composability of model is still a problem to overcome. Many solutions propose the use of ontology and SOA architectures in the context of distributed simulation. This work presents a solution to compose simulation models in the context of supply chain simulation. The proposal presents a network ontology that conceptualizes different aspect to taking into account when a federation for supply chain is developed.
\end{abstract}

Keywords: Distributed simulation. Composability. Ontology network. Supply chain simulation. DEVS.

\section{INTRODUCTION}

In recent decades, organizations have found the need to change their structures in order to remain agile and competitive. Among these new structures, organizational networks have become popular because of the benefits they provide to their participants. Supply chain (SC) is one of the most popular organizational networks where its members perform alliances to achieve higher goals than they would do isolated.

The success of a SC depends on coordination of participant activities to make material, information and financial flows efficient. Simulation of SC is a fundamental tool to meet the requirement for success. A SC simulation project could be very costly and consumed time, because participating members are not under a central authority and they do not want to expose theirs data to other organizations. In general, this problem is solved employing distribute simulation which promotes reuse of simulation program applied by individual

\footnotetext{
1 Dra. en Ingenieria, Universidad Tecnológica Nacional Facultad Regional Santa Fe (UTN), CIDISI, Argentina. E-mail: mmgutier@frsf.utn.edu.ar.

2 Dr. en Ingeniería, Universidad Tecnológica Nacional - Consejo Nacional de Investigaciones Científicas y Técnicas, Instituto de Desarrollo y Diseño (CONICET, INGAR), Argentina. E-mail: hleone@santafeconicet.gov.ar.
}

Iberoamerican Journal of Industrial Engineering, Florianópolis, SC, Brasil, v. 5, n. 10, p. 55-69, 2013. 
members and minimizes the time in build supply chain simulation, preserving at the same time the local autonomies and privacy of logistics data.

The modeling and simulation community has shown a growing interest towards building simulation models through model composition (GUSTAVSON; ROOT, 1999; KASPUTIS; NG, 2000; VERBRAECK, 2004; TOLK, 2006). The increased progress of the component-base technology in software engineering, has allowed developing flexible computational environments, where the reuse and the construction of the model as a puzzle are the major advantages, enabling the construction of distributed simulation model (VERBRAECK, 2004). While this schema is good to be applied in SC simulation, the models composability problem emerges.

There are different levels of composability: syntactic, semantic and pragmatic. Syntactic composability refers to the components' connections and communication. It focuses on the implementation aspects of each simulation component and guarantees the correct and loosecoupled connections between components. Semantic composability addresses whether the combined computation of the simulation model is semantically valid. It is concerned with whether the models that make up the composed simulation system can be composed in a meaningful way and the composition is valid (WEISEL; PETTY; MIELKE, 2003, 2004). Pragmatic composability addresses whether components are aware of the simulation context in which they are running (TOLK, 2006), in this case components know about intent of the use of data (ZEIGLER; PRAEHOFER; KIM, 2007).

In previous works authors proposed $\mathrm{DE}^{2} \mathrm{M}$ an environment for enterprise model (EM) modeling and simulation, where from a conceptual enterprise model is obtained a simulation model based on DEVS formalism (ZEIGLER; PRAEHOFER; KIM, 2000), which can run on local environment and in a distributed one (GUTIERREZ; LEONE, 2012). In this case, the same DEVS models are transferred to the DEVS-based distributed simulation environment with extensions in their message structures to allow them to exchange information in, as well as being time-managed by, the distributed environment. An example on a SC distributed simulation has been presented in (GUTIERREZ; LEONE, 2007, 2008).

The use of HLA standard (IEEE 1516-2000, 2000) guarantee the syntactic composability, however, the construction of federation is not solved. An important issue in addressing composability, in particular semantic composability, is expressing domain or component knowledge in an unambiguous, standardized format. Ontologies are used to 
organize the knowledge representation to capture objects information in a particular domain (GÓMEZ-PÉREZ; FERNANDEZ-LOPEZ; CORCHO, 2004). Following with this research, this work overcomes the problem of constructing a federation guaranteeing not only syntactic but also semantic composition. With this aim, the proposal presents an ontology network to provide a tool to develop a SC federation. This network is composed of four ontologies that involve different aspects of a SC federation.

This work is organized as follow. In the next section, the main concepts to this paper are defined: Ontology network and $\mathrm{DE}^{2} \mathrm{M}$ environment. Then the ontology network developed is shown and its components are described. In section 4 an example of a supply chain is presented. Finally, conclusions and future research direction are discussed.

\section{FOUNDATION}

\subsection{Ontology Network}

An ontology network is a set of ontologies related together via a variety of different relationships such as mapping, modularization, version, and dependency. The elements of this set are called Networked Ontologies (ALLOCCA; D’AQUIN; MOTTA, 2009).

An ontology network differs from a set of interconnected individual ontologies in the relations among ontologies since in an ontology network the meta-relationships among the networked ontologies are explicitly expressed (DÍAZ et al., 2012). There are some models that cover both the syntactic and semantic aspects of dealing with ontology relationships in networked ontologies. In the DOOR (Descriptive Ontology of Ontology Relations) ontology, general relations between ontologies, such as includedIn, equivalentTo, similarTo, and versioning were defined by using ontological primitives and rules (ALLOCCA; D'AQUIN; MOTTA, 2009).

Concerning a support for implementing and management ontology networks, the NeOn Project can be mentioned (http://www.neon-project.org). NeOn has developed an open service-centered reference architecture for managing the complete life cycle of networked ontologies and metadata. This architecture is realized through the NeOn Toolkit and complemented by the $\mathrm{NeOn}$ methodology, which is a scenario-based methodology that supports the collaborative aspects of ontology development and reuse (SUÁREZFIGUEROA, 2010).

Iberoamerican Journal of Industrial Engineering, Florianópolis, SC, Brasil, v. 5, n. 10, p. 55-69, 2013. 
From a model integration point of view, within an ontology network, each ontology conceptualizes a specific domain and plays a particular role. Then, the main advantage of using an ontology network is the conceptualization of a given domain in a modular way. The networked ontology is small enough to be understandable by any person and its maintenance is easy. In addition, several ontology designers could work on different networked ontologies concurrently.

\section{2 $\mathrm{DE}^{2} \mathrm{M}$ environment}

Figure 1 shows the architecture of the environment called $\mathrm{DE}^{2} \mathrm{M}$ - meaning Distributed and Executable Enterprise Model. It is a two-layer architecture where the simulation process details are hidden. The Conceptual Model Layer characterizes the knowledge about an organization in term of processes, tasks, resources, and objectives. The Simulation Layer represents the behavior of the organization in term of events, ports, process, queue, state transition, and simulation time.

Figure 1-DE2M architecture

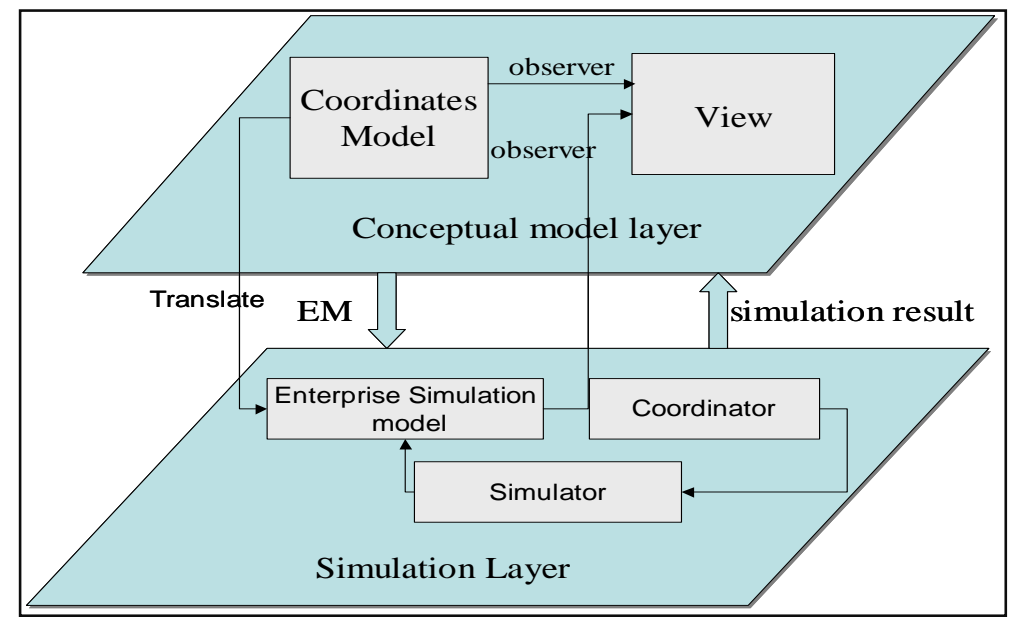

The Conceptual model layer has functions to develop the EM using a business-processoriented language. This model does not have simulation information. The simulation layer provides functionality to create the SM, to execute it either locally or in a distributed environment, and to compute metrics. It is responsible for translating the conceptual model in a simulation model without user intervention. At the Simulation layer, the Enterprise Simulation Model component is based on the DEVS formalism.

The Coordinator component is the engine of the simulation model. It covers the root coordinators. There are two root-coordinators: one for a local simulation (Coordinator class)

Iberoamerican Journal of Industrial Engineering, Florianópolis, SC, Brasil, v. 5, n. 10, p. 55-69, 2013. 
and the other for the distributed environment (CoordinatorE2M class). The Simulator component covers the engine associated with each building-block participating in SM. Then, each atomic model has a simulator associated and each coupled model has a coordinator associated. Finally, the View component is made up of entities that appear in the user interface showing the concepts (task, resources, states, etc.), graphics and results.

\section{SCFHLA ONTOLOGY NETWORK}

This section introduces the ideas of conceptual modeling and capturing the resulting artifacts in a systematic way. A conceptual model is the abstract and simplified representation of systems for some specific purpose by languages, figures, tables, or other suitable artifacts. Hofmann observes that to compose simulation systems meaningfully and achieve valid interoperability among the simulation systems and underlying models, the alignment and consistent comprehension should be reached at the conceptual model level (HOFMANN, 2004). Similar observations were made within the Simulation Interoperability Standards Organization (SISO) within their Conceptual Modeling Study Group (BORAH, 2006). The ontology network proposed (Figure 2) is used to support the design of conceptual model of a SC federation taking into account different aspects that have to be modeled.

Figure 2 - SCFHLA ontology network

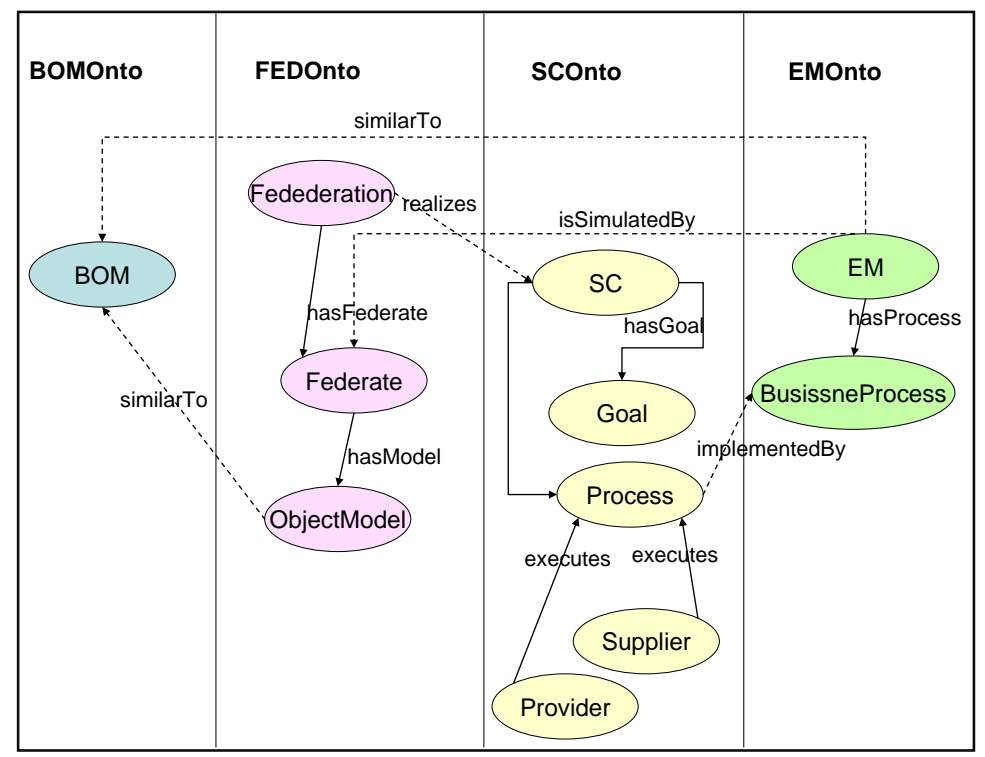

According with FEDEP (HLA FEDEP MODEL, 1999), the design of a federation involves seven steps where to describe key aspects such as: objectives, conceptual object model and federation object model among others. In this way, objectives must agree with

Iberoamerican Journal of Industrial Engineering, Florianópolis, SC, Brasil, v. 5, n. 10, p. 55-69, 2013. 
supply chain objectives and the variables involves in metric that realized the objective must be represented as a conceptual entity. Also, there will be an agreement between conceptual object model and simulation object model. Then, when a federate is added a federation a new vocabulary is introduced defined by its SOM object model. In the same way, when a pattern of interplay is defined, it must be interactions and object classes in the FOM realizing such pattern. In order to validate these and other restriction and provide a common vocabulary to define a federation, the ontology network has been defined. This network provides a modular way to describe the different domains involved.

The FEDOnto ontology abstracts the concepts to generate the conceptual model of a federation. A federation has federates, each federate has an object model associated that represents objects that federate can recognize. A federation realizes a supply chain conceptualized by SCOnto ontology (BOHM, LEONE, HENNING; 2007). A supply chain has goal and can be represented by process such as those defined in SCOR model (SCOR, 2006). Each process is implemented by a business process modeled with EMOnto. BOMOnto is a semantically enriched BOM which is a schema for federation conceptual model. Next subsections describes BOMOnto, FEDOnto and SCOnto ontologies in the network. EMOnto will not be described because it was presented in previous work (GUTIERREZ; LEONE, 2012) as part of $\mathrm{DE}^{2} \mathrm{M}$ environment. The ontologies presented in this paper are useful in achieve the agreement on FOM through a conceptual modeling way.

\subsection{FEDOnto}

This ontology conceptualizes an HLA federation. It is used to describe a federation when a distributed simulation is being developed. HLA is the most widely used architecture for distributed simulations today. It provides a simulation environment and standards for specifying simulation parts via Simulation Object Models (SOMs) and interactions between simulation parts via Federation Object Models (FOMs). Figure 3 shows the FEDOnto ontology. An HLA simulation is named Federation, which is composed out of Federates, or simulation parts. Through SOMs and FOMs, HLA intends to formalize how federates function and how they interact, both are Objects model. An Object model is composed out of a set of interaction and a set of object class. Interaction has parameters and Object class has Attributes.

Iberoamerican Journal of Industrial Engineering, Florianópolis, SC, Brasil, v. 5, n. 10, p. 55-69, 2013. 
Figure 1 - FEDOnto Ontology

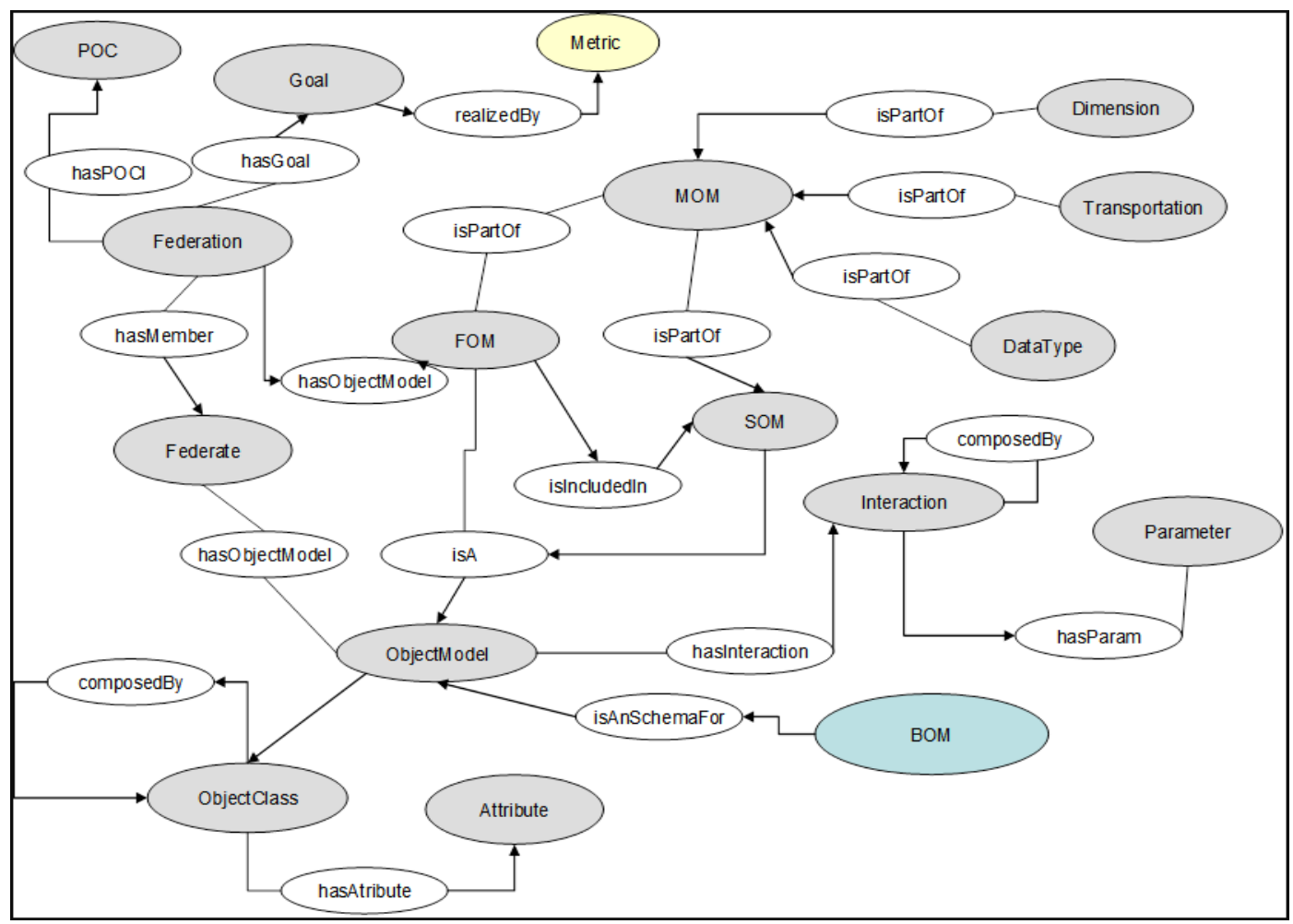

Each Federation must have a FOM associated and a Federate can have either a FOM or a $S O M$ associated. The FOM associated to a Federation must be included in the SOM of each federate that conform the federation; this restriction is expressed in Equation 1. A Federation has a Goal associated, which is realized by metric. It has been defined metric in the context of supply chain such as Order fulfill, cycle time order, supply chain cost, among others.

$\mathfrak{I} \mid=(\forall \mathrm{x}$ federation $(\mathrm{x}) \wedge \operatorname{hasObjectModel}(\mathrm{x}, \mathrm{o}) \Rightarrow(\forall \mathrm{y}$,

$($ federate $(\mathrm{y}) \wedge \operatorname{hasObjectModel}(\mathrm{y}, \mathrm{s})) \Rightarrow \operatorname{isIncludedIn}(\mathrm{o}, \mathrm{s})))$

\subsection{SCOnto}

This ontology conceptualizes a supply chain according to SCOR model SISO. These concepts there are related with concepts in FEDOnto and BOM ontology. Figure 4 shows the SCOnto. A SupplyChain is composed of Process and has a Goal which is realized by metrics. A Metric has variables each one uses a specific measurement unit. A Process has outputs and inputs associated. Both are variables used to calculate metrics. Deliver, Make, Plan, Return and Source are subclasses of Process. Supplier, Provider and Marker are Roles that a federate can play into a supply chain. These roles execute processes. 
Figure 2 - SCOnto ontology

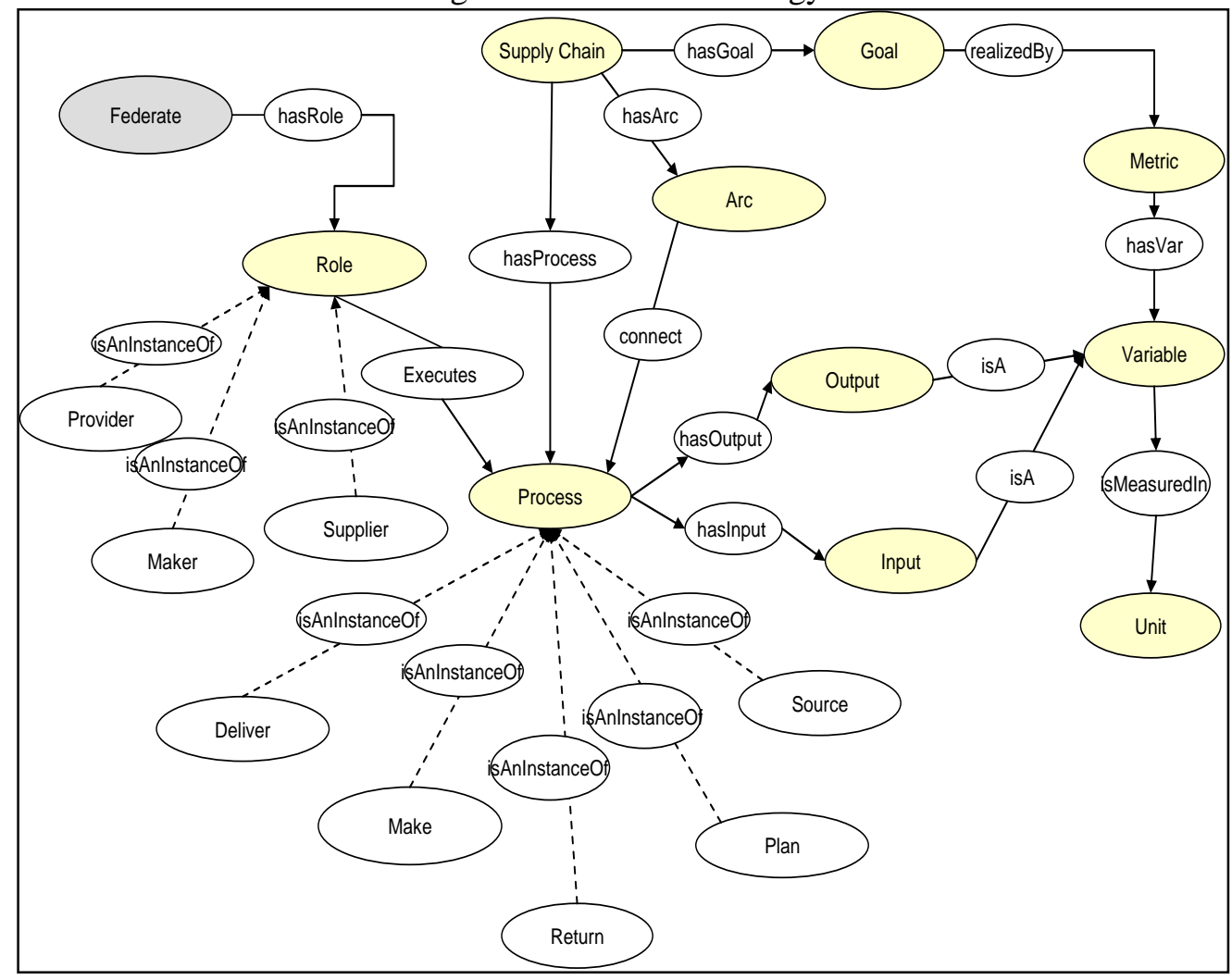

A variable used in a metric must be similar to an attribute defined in the object model of a federate. A supply chain can be described as a graph with arcs and nodes, where nodes are processes defined in SCOR model and arcs represent connection between processes. This work uses SCOR model because it is a well known model widely uses and it defines metrics used to measure supply chain. For example one metric to measure the customer satisfaction is fill rate which is calculated as the ration between completed orders and total orders in the supply chain. This metric is instantiated in the ontology and related with other concepts restricted the vocabulary used when the federation objectives are defined. Section 4 shows this concept with an example.

\subsection{BOMOnto}

The BOM is a concept created by Simulation Interoperability Standards Organization (SISO) to enable composability and reuse for High Level Architecture (HLA) simulations. The BOM development started in 1997, and since 2006 it is a SISO standard (SISO, 2006). It is considered as a data model to describe entities, relations and types. However, the requirement for this project bases on supply chain perspective. We would like to capture and

Iberoamerican Journal of Industrial Engineering, Florianópolis, SC, Brasil, v. 5, n. 10, p. 55-69, 2013. 
model the meaning (semantics) and behaviour (pragmatics) of supply chain domain. Follow the ideas presented in (BORAH, 2006), BOMOnto has been designed as part of an ontology network where the concepts from supply chain were introduced and related one to another.

Figure 5 shows BOMOnto ontology where the main concept is BOM represented the data model. It is composed of Entities and Pattern of interplay. The behaviour of an entity is represented through State machine which has state and transition.

Figure 3 - BOM Ontology

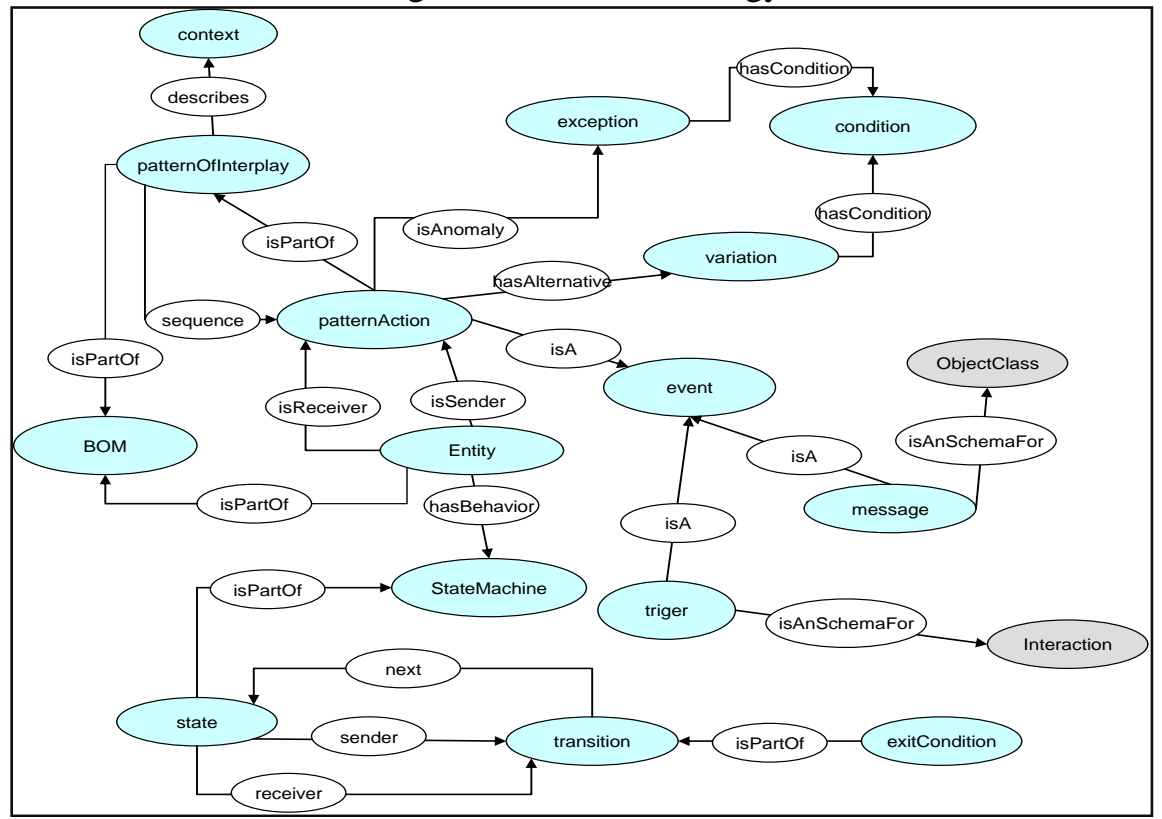

The PatternOfInterplay is composed of a sequence of PatternAction represented entities that sends/receives events. There are two type of event: message and trigger. First is a schema for publish/subscribed interaction between two federates. In this case, the entity which is sender of that event must be the publisher of an attribute belonging to an object class. In the same way the entity which is receiver of that event must be the subscriber of that attribute. This restriction is derived from the HLA operation.

\section{DEFINING A SUPPLY CHAIN FEDERATION}

In order to develop an example, we use a prototype of a tool 3 (in development) that uses the network ontology to define a federation (the user interfaces are written in Spanish). This tool proposes the definition of a federation in a collaborative way and follows the steps

3 http://dicofhla.no-ip.org/webProyect/WebContent/View/login.html

Iberoamerican Journal of Industrial Engineering, Florianópolis, SC, Brasil, v. 5, n. 10, p. 55-69, 2013. 
described in FEDEP. Then in order to carry out the third step it is proposed use BOM (MOJTAHED; ANDERSSON; KABILAN, 2008) conceptual model.

As an example, consider a supply chain with two participants: one is a yerba mate factory and the other is the distributor of such product. In order to generate the distributed simulation of such a supply chain, the first step is to create the federation and defines its goal. Then members are added to the federation recently created and must be agree on FOM definition.

Members can upload its SOM, this action cause that ontologies were instantiated and filled with the vocabulary existing in SOM. This vocabulary will be used to define conceptual model, which in term generates the FOM used by federation in run time. Figure 6 shows the snapshot of the environment where the YerbaMateSCH federation and MakeFederate federate have been created. We have used the name MakeFederate to represent the factory and SourceFederate to represent the distributor. So Factory is associated with the role Maker and the distributor is associated with the role Supplier. Suppose that the federate has a SOM with the following definition:

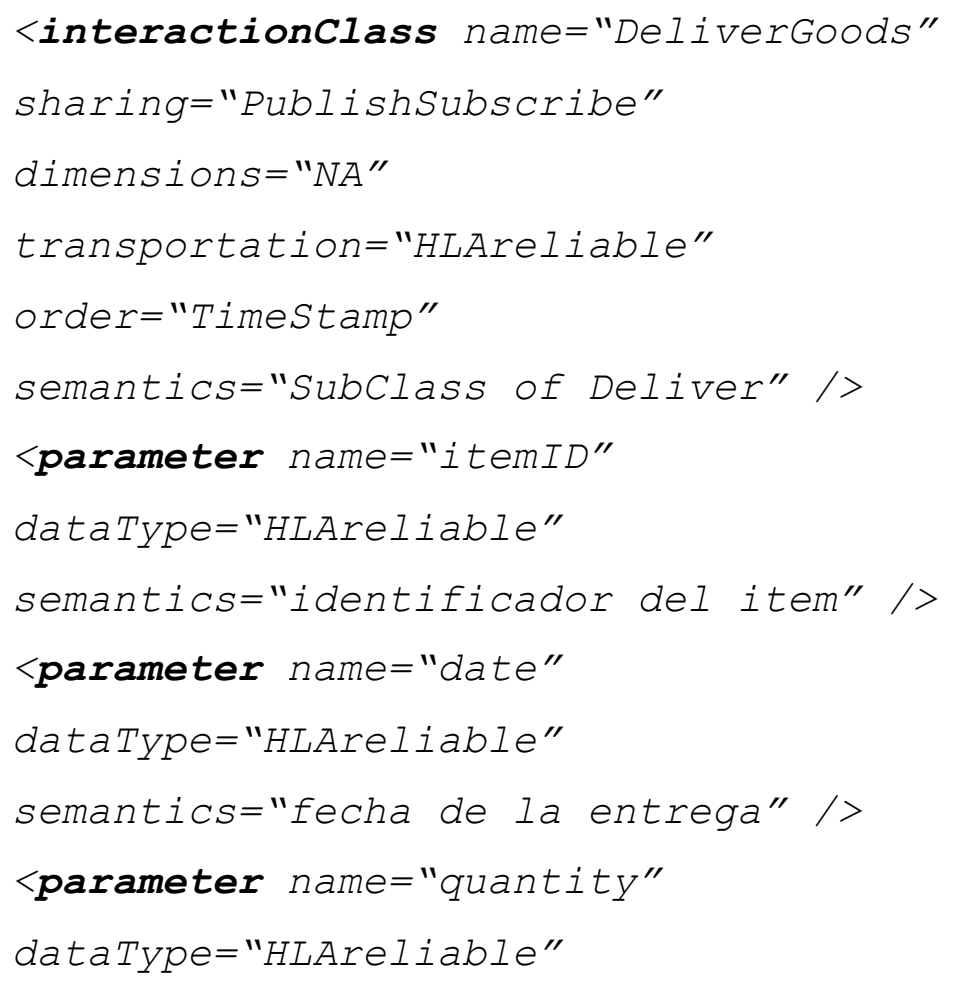

When this SOM is uploaded causes the FEDOnto and BOMOnto are instantiated as is shown in Figure 6. 
Figure 4 - Welcome Snapshot of Dicof-HLA application

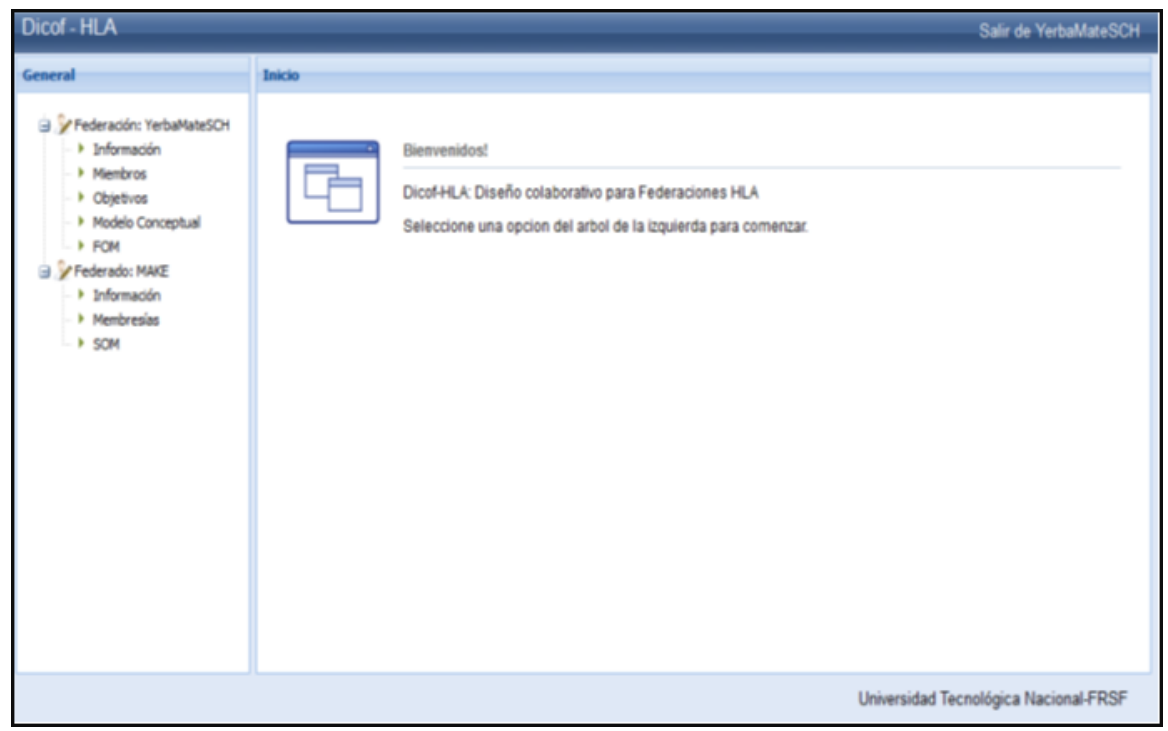

Then, in order to define metrics as goal for federation, member can select predefined metrics or define a new one. Figure 7 shows the snapshot to select metrics. Suppose we select fill rate (in the snapshot appear as Orden cumplida Correctamente) as metric for the federation. This metric is instantiated as is shown in Figure 8.

Figure 5 - FEDOnto Ontology instantiation

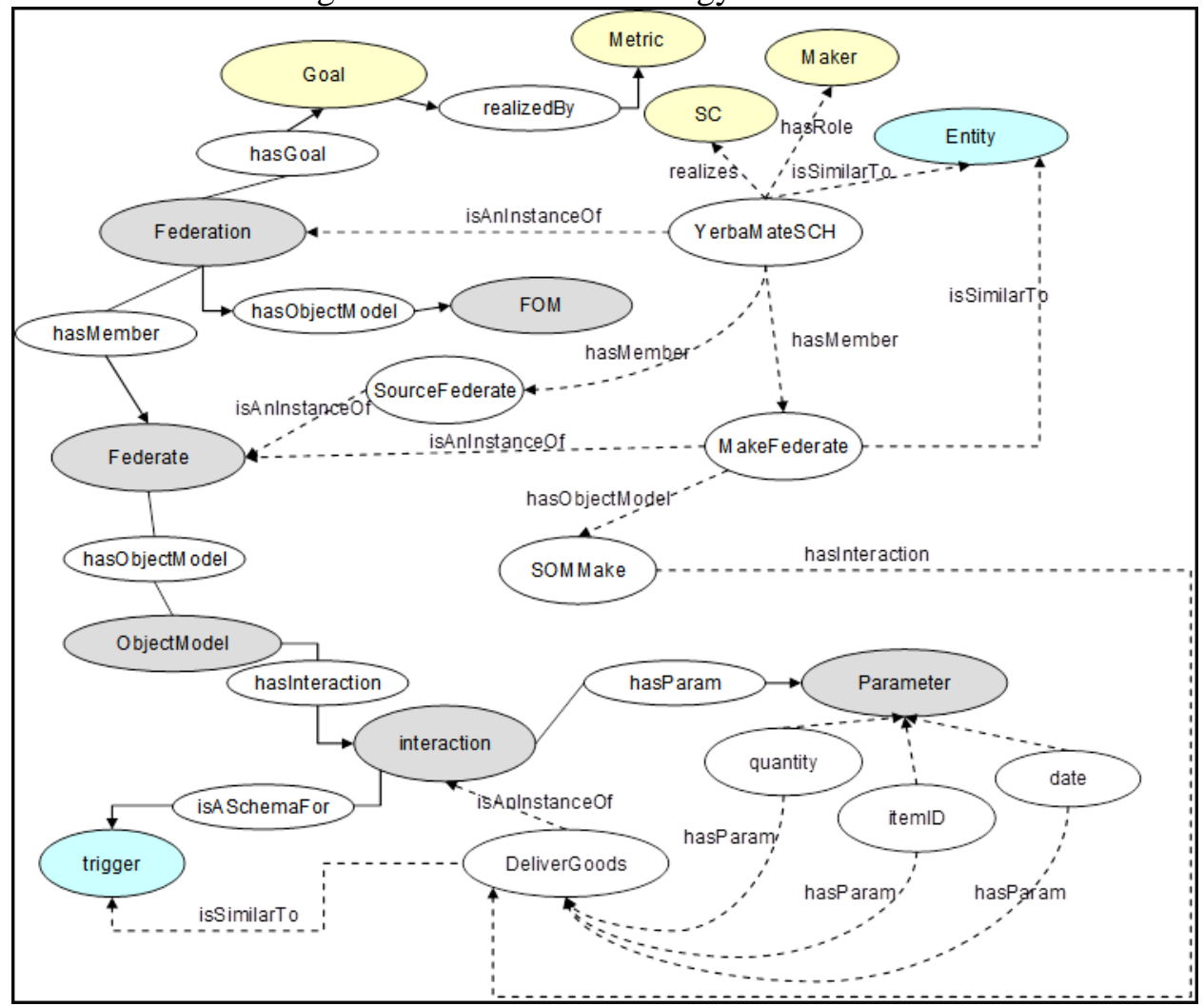

Iberoamerican Journal of Industrial Engineering, Florianópolis, SC, Brasil, v. 5, n. 10, p. 55-69, 2013. 
One of the step is created the FOM that will be used in federation. The tool provide an automatic generation validating the conceptual model that it was generated and checking if FOM is included in each SOM uploaded. Equation 2 describes the restriction that FOM must be meet to be included in a SOM.

$$
(\mathrm{FOM}(\mathrm{x}) \wedge \operatorname{SOM}(\mathrm{y})) \Rightarrow(\forall \mathrm{z}(\operatorname{objectClass}(\mathrm{z}) \wedge \operatorname{hasObject}(\mathrm{x}, \mathrm{z})) \Rightarrow \operatorname{hasObject}(\mathrm{y}, \mathrm{z}))
$$

Some restrictions are defined for attributes, interaction and parameters.

Figure 6 - Selection of metric for YerbaMateSCH federation

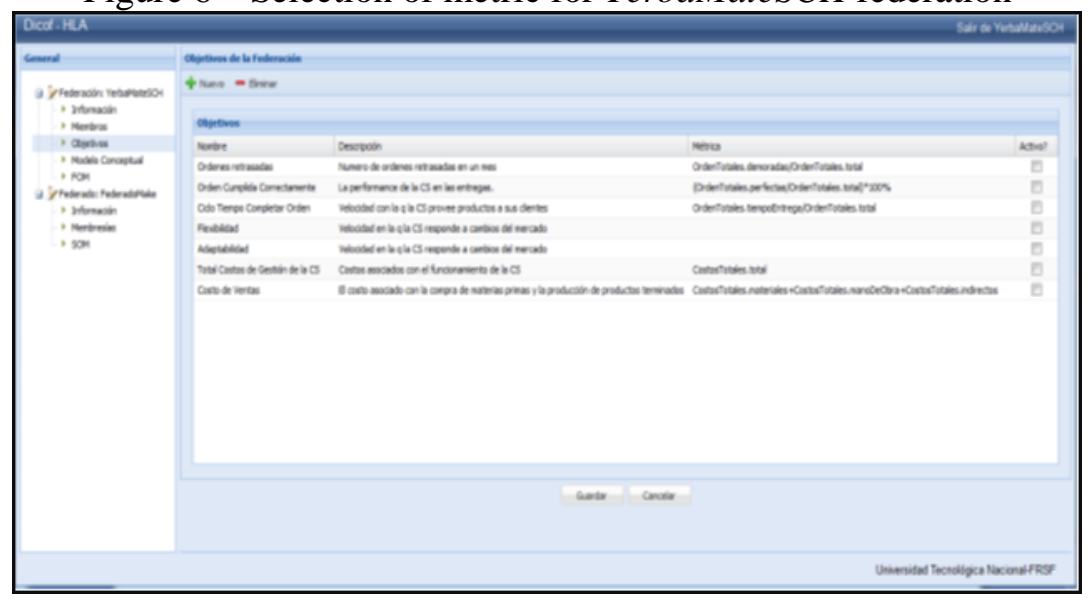

\section{CONCLUSION}

This work has shown the progress in the definition of an ontology network which purpose is to conceptualize the distributed simulation in supply chain domain. The modularization that this network provides let us concentrate the attention on a particular domain and incrementally build a more general model relating different ontologies. The concepts related with supply chain, conceptual data model and HLA data model domains were presented.

Mainly, this work focused on describing and related different domains to support semantic interoperability when a supply chain distributed simulation is generated. So, FEDOnto describes a federation and the metadatas use in FOM and SOM object model when a federation is defined. BOMOnto, describes the concepts used to model a conceptual data model for federation interoperability. EMOnto is a vocabulary used to define enterprise model (Figure 9). 
Figure 9 - Fill rate metric and SCOnto instanciation

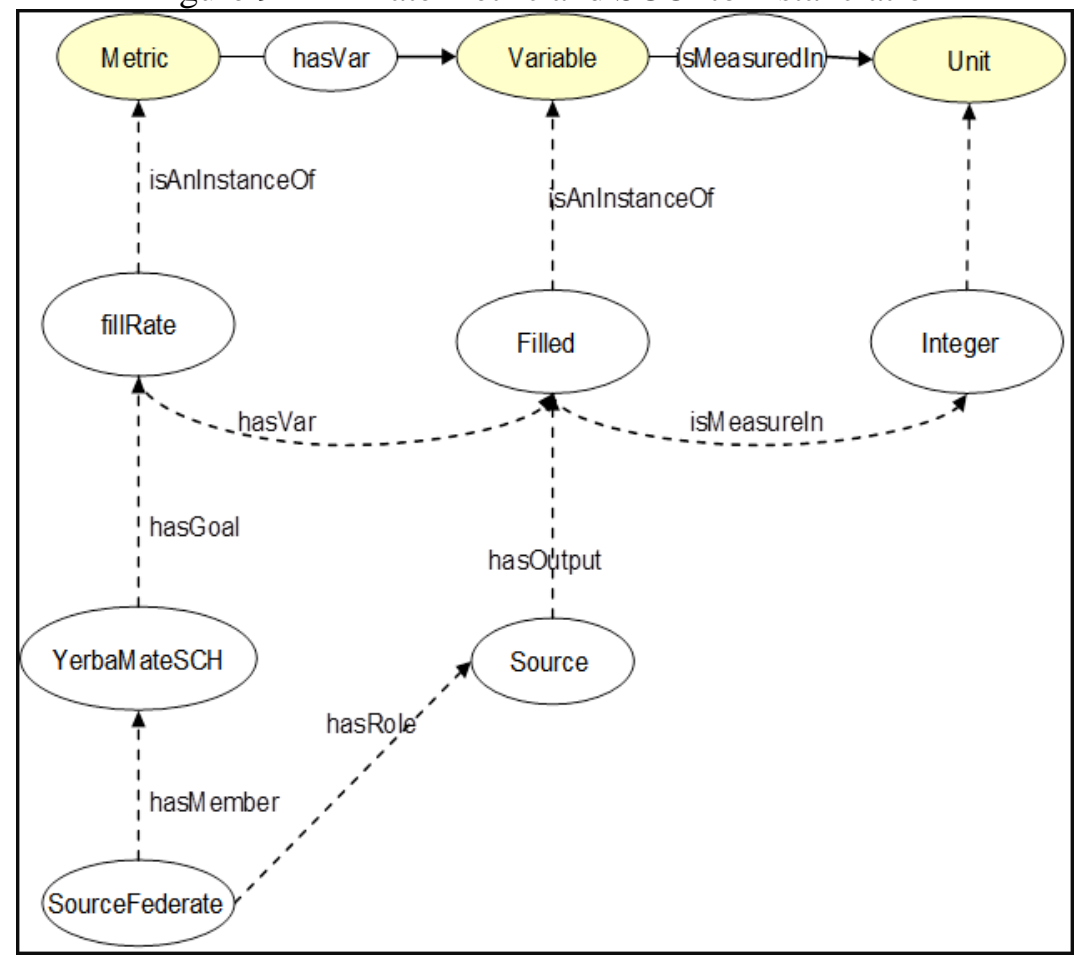

As future work we are working on definition of axioms and logical rules that restrict the model. Considering that the OWL language is the standard for implementing an ontology and this is not always enough to do some deduction, then it is needed to combine OWL with other representation formalism as rules. One of the integration approaches is the Semantic Web Rule Language (SWRL), which provides the ability to express Horn-like rules in terms of OWL concepts (O’CONNOR; KNUBLAUCH; MUSEN, 2005).

\section{REFERENCES}

ALLOCCA, C.; D'AQUIN, M.; MOTTA, E. DOOR-towards a formalization of ontology relations. Proceeding..., Int. Conference on Knowledge Engineering and Ontology Development, p. 13-20, 2009.

BÖHM A.C., LEONE H.P. y HENNING G.P. Industrial Supply Chains: Performance Measures, Metrics and Benchmarks. En: Computer-Aided Chemical Engineering 24, Paises Bajos: Elsevier, 2007, pp. 757-762

DÍAZ, A.; MOTZ, R.; ROHRER, E.; TANSINI, L. An Ontology Network for Educational Recommender Systems. Educational recomender systems and technologies. Practices and challenges. IGI Global, Chapter 4, p. 67-93, 2012. 
GÓMEZ-PÉREZ, A.; FERNANDEZ-LOPEZ, M.; CORCHO, O. Ontological Engineering. Springer, Heidelberg, 2004.

GUSTAVSON, P., ROOT, L. Object Model use cases: a mechanism for capturing requirements and supporting BOM reuse. In Spring Simulation Interoperability Workshop, Orlando, USA, (1999)

GUTIERREZ, M.; LEONE, H. Adapting an Executable Enterprise Model Environment for HLA. Proceedings ..., EMSS 2007 European Modeling and Simulation Symposium. Bergeggi Italia, 2007.

GUTIÉRREZ, M., LEONE, P.: DE ${ }^{2}$ M: A Solution for Analyzing Supply Chain. In WSC 2008. Miami, Florida. EEUU. p. 1420-1428, 2008.

GUTIERREZ, M.; LEONE, H. DE ${ }^{2}$ : an environment for developing distributed and executable enterprise model. Journal of Advances in Engineering Software, v. 47, n. 1, p. 80-103, 2012.

HLA FEDEP MODEL. Version 1,5. December 8, 1999. DMSO. Retrieved from: <https://www.dmso.mil-/public/library/projects/hla/guidelines/fedepv15.pdf >

HOFMANN, M. Challenges of model interoperation in military simulations. In Simulation, v. 80, n. 12, p. 659-667, 2004.

IEEE 1516-2000. IEEE Standard for Modeling and Simulation (M\&S) High Level Architecture (HLA). Framework and Rules, 2000.

BORAH, J.J. SISO-REF-017-2006 simulation conceptual modeling (SCM) SG. Final report. 2006. Retrieved from: <http://www.sisostds.org>

KASPUTIS, S.; NG, H. Composable Simulations. Proceedings..., of the Winter Simulation Conference, p. 1577-1584, Orlando, USA, 2000.

O'CONNOR, M.; KNUBLAUCH, H.; TU, S.; MUSEN M. Writing rules for the semantic web using SWRL and Jess. Proceedings..., in the 8th International Protégé Conference, Protégé with rules Workshop, 2005.

PETTY, M.; WEISEL, E.; MIELKE, R. Overview of a theory of composability. Virginia Modeling Analysis \& Simulation Center, Old Dominion University, 2004.

SCOR. Version 8.0 Overview. 2006. URL: http://www.supply-chain.org accessed 02/08.

SISO. Homepage of Base Object Model. Retrieved from: 〈www.boms.info $>$

SUÁREZ-FIGUEROA, M. NeOn Methodology for Building Ontology Networks: Specification, Scheduling and Reuse. Thesis Doctoral, Facultad de Informática - Universidad Politécnica de Madrid, 2010. 
TOLK, A.What Comes After the Semantic Web - PADS Implications for the Dynamic Web. Proceedings..., of the $20^{\text {th }}$ Workshop on Principles of Advanced and Distributed Simulation, Singapore, p. 55-62, 2006.

TOLK, A. What Comes After the Semantic Web - PADS Implications for the Dynamic Web. Proceedings..., of the $20^{\text {th }}$ Workshop on Principles of Advanced and Distributed Simulation, Singapore, p. 55-62, 2006.

V, MOJTAHED, B. ANDERSSON, V. KABILAN. BOM++: a semantically enriched BOM [C]. 08S-SIW-050, 2008.

VERBRAECK, A. Component-based Distributed Simulations. The Way Forward? In Proceedings..., of 18th Workshop on Parallel and Distributed Simulation, Kufstein, Austria, p. 141-148, 2004.

WEISEL, E.; PETTY, M.; MIELKE, R. Validity of Models and Classes of Models in Semantic Composability. Proceedings ..., of the Fall 2003 SIW, Orlando FL., 2003.

ZEIGLER, B.; HAMMONDS, P. Modeling and simulation-based data engineering. Introducing pragmatics into ontologies for net-centric information exchange. Elsevier Academic Press, 2007.

ZEIGLER, B.; PRAEHOFER, H.; KIM, T. Theory of Modelling and simulation. Integrating Discrete event and continuous complex dynamic system. Second edition. Academic press, 2000.

Originais recebidos em: 26/10/2013

Aceito para publicação em: 15/04/2014 